\title{
Australian labour account: Linking production to people and jobs
}

\author{
Michael Smedes* and Jennifer Humphrys \\ Australian Bureau of Statistics, Belconnen, Australia
}

\begin{abstract}
This paper describes how the Australian Labour Account supports macro-economic analysis of peoples' participation in employment and related production over time. Development of Labour Accounts have provided an opportunity to significantly improve the quality of aggregates such as the number of jobs occupied within each industry, measures of hours worked, and labour productivity growth. Finally, it provides an opportunity to further emphasise the household experience within the system of economic accounts, linking from production activities to important demographic and socio-economic issues.
\end{abstract}

Keywords: System of National Accounts, labour statistics, productivity measurement, jobs, hours worked, production

\section{Introduction}

The Australian Labour Account supports macroeconomic analysis of peoples' participation in employment and related production over time. Its development provides an opportunity to significantly improve the quality of aggregates such as the number of jobs occupied within each industry, measures of hours worked, and labour productivity growth. It provides an opportunity to further emphasise the household experience within the system of economic accounts, linking from production activities to important demographic and socio-economic issues.

The System of National Accounts (SNA08) does not currently provide for a detailed articulation of labour, this stands in stark contrast to the guidance provided on other inputs into the production process such as produced capital, financial capital, and goods and services. This is a major gap in the system of accounts with detrimental consequences for the utility and relevance of the national accounts.

The concepts and definitions underlying the Australian Labour Account are built on International

*Corresponding author: Michael Smedes, 45 Benjamin Way, Belconnen ACT, 2617, Australia. Tel.: +61 26252 7010; E-mail: Michael.smedes@abs.gov.au.
Labour Organisation (ILO) fundamentals, and expands them to ensure consistency with the SNA08 production boundary. The result provides a set of core macroeconomic labour market time series variables derived through data integration.

\section{Purpose}

The Australian Labour Account has been developed to provide a framework for integrating labour related data from a number of sources (including household survey, business survey, and administrative data). The result is consistent estimates of key labour market variables, which more effectively enable the description and analysis of the state and dynamics of the Australian labour market. These core variables can help users make sense of seemingly inconsistent labour related data, which are often based on different reference periods, populations, concepts, definitions and methodologies.

These inconsistencies are magnified when data are dis-aggregated by industry or sector, or in analysis requiring the combination of data from both business and household sources, for example combining output and hours worked by industry to derive industry productivity growth rates. There is a risk that users may draw inappropriate conclusions from the use of different labour statistics without an informed understanding of which data to use in which circumstances. 


\section{Labour Account framework}

The Labour Account provides a conceptual framework through which existing labour market data from diverse sources can be confronted and integrated, with the aim of producing a coherent and consistent set of aggregate labour market statistics.

The Labour Account helps address data coherence by:

- bringing together related labour statistics from multiple sources in a single set of tables;

- applying a consistent set of concepts across the data to explore statistical anomalies;

- making transparent adjustments to data to offset conceptual and scope differences; and

- making further informed and documented data adjustments to provide a balanced set of labour statistics.

The Labour Account consists of four quadrant tables: jobs, persons, volume and payments (see Fig. 1). Data in each table are available quarterly, and for 19 high level industry groupings, and annually for 86 sub industries.

\section{Conceptual scope}

Accounting conventions are necessary to define the scope and treatment of activities that occur within the economy. The production and residency conventions adopted in the Australian System of National Accounts (ASNA) are used in the Australian Labour Account to determine the scope of activities covered, and the size of the economy measured.

The scope of the Australian economy defined by these conventions embraces the activities of all enterprises resident within Australia's economic territory engaged in the production of goods and services, which fall within the scope of the National Accounts production boundary. The Labour Account relates to the employment of all persons in jobs created by those enterprises. In this context:

- an enterprise is a productive unit maintained and controlled by one or more households, corporations or "quasi-corporations" that are resident in Australia's economic territory, enterprises include (for example):

* businesses operated by unincorporated selfemployed trades persons,

* family operated farms,

* large corporations such as the major commercial banks and supermarket chains,
* Government departments and agencies like Centrelink and the Australian Taxation Office, and

* schools and hospitals operated by the state, or by religious organisations and charities.

- the National Accounts production boundary embraces the production of all goods and services, with the exception of services produced by household-controlled enterprises solely for consumption by the household itself. This exclusion relates to (for example) the cooking of meals for household members, household washing and cleaning and care of dependents. However, the "shelter services" provided by owner occupied dwellings are included within the production boundary.

- Australian economic territory includes all geographies under the control of the Australian Government, i.e. the Australian mainland, off-shore islands, Antarctic territories, Australian embassies and military establishments in other countries, and Australia's exclusive maritime economic zone. It excludes foreign embassies and military establishments in Australia.

- an enterprise is considered "resident" if the "economic interest" of its controlling institutional unit (household, corporation or quasi-corporation) is centred in the Australian economic territory.

\section{Jobs}

The concept of a job is central to understanding the impact of globalisation and digitalisation on households. Changes to production arrangements have altered the labour experiences of citizens with impacts on job security, skill needs, labour compensation and more. A better understanding of jobs allows us to better understand the intersection between production and the labour force.

Compiling the Labour Account and in particular developing a 'jobs' quadrant also sets us up to more completely inform on the nature of work in Australia, including work that takes place outside of the SNA production boundary. The framework also recognises other types of work such as unpaid household work and volunteering to be introduced in an extension to the accounts. Thus, illustrating all types of work undertaken by households and persons together.

A job is a set of production related tasks that can be assigned to and undertaken by a person, and for which they are usually, but not necessarily, remunerated either 
JOBS

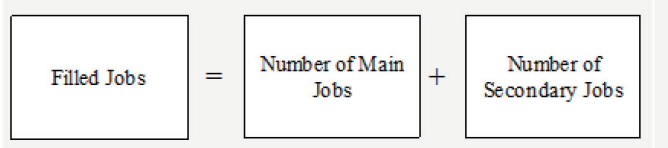

$+$

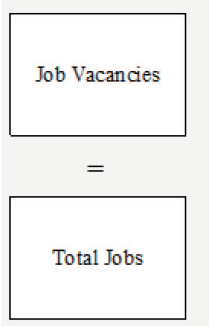

VOLUME
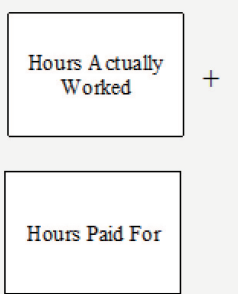

$=$

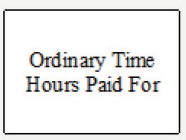

$+$

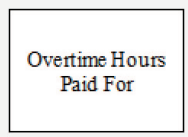

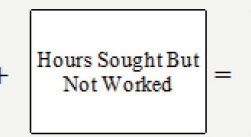

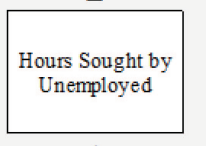

$+$

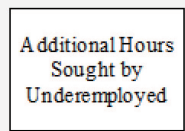

Underemployed
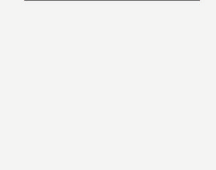

\section{A vailable Hours} of Labour Supply

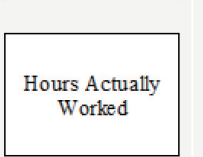

/

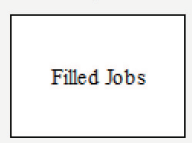

$=$

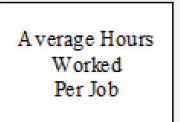

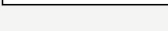

PERSONS

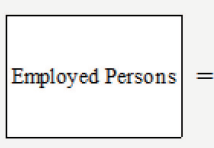

$+$

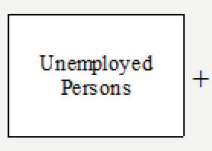

$=$
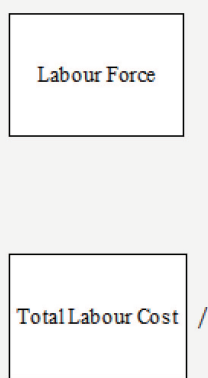

$=$

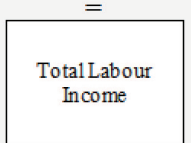

$+$

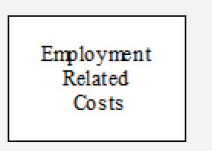

$+$

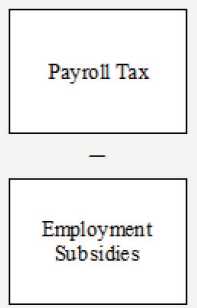

PAYMENTS No. of Main Jobs
(Total Economy
Level)
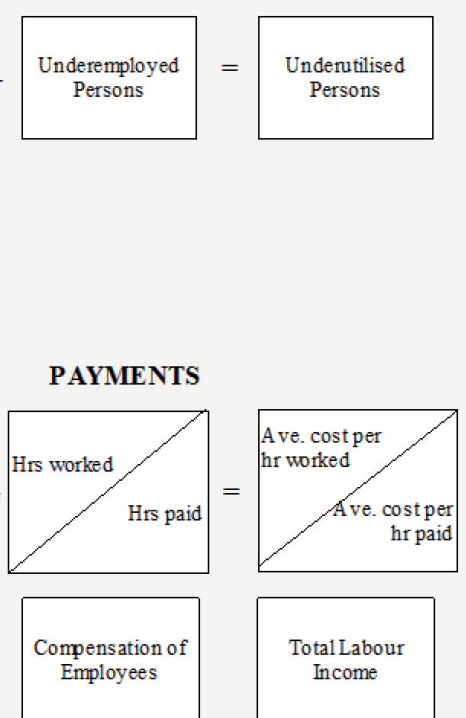

$+$

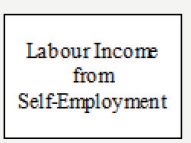

$=$
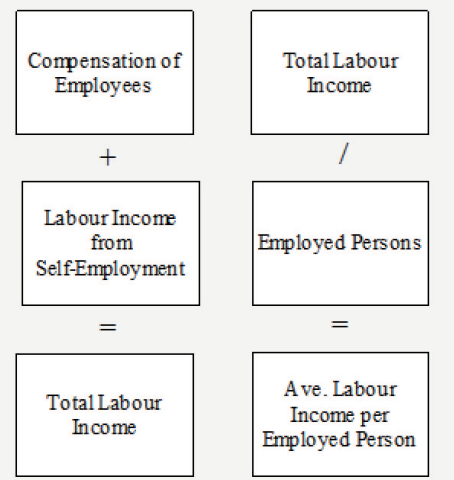

/

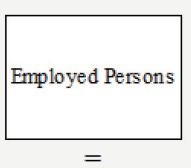

$=$

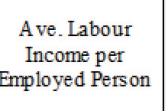

Fig. 1. Australian Labour Account: Identity relationship diagram.

in money or in kind. Jobs are created by enterprises. A "filled job" exists where an enterprise establishes explicit or implicit employment contracts with individual persons to undertake the job. Estimates of movements in the number of jobs in the economy provide a measure of labour market performance and capacity.

Defining a job is difficult. In the language used in national accounts, a job is an economic activity through which people engage in production. However, a dictionary definition is perhaps easiest to comprehend: a task or piece of work, especially one that is paid.

In the context of the Australian Labour Account, a job is a set of production related tasks that can be assigned to and undertaken by a person, and for which they are usually, but not necessarily, remunerated either in money or in kind.

The Jobs quadrant in the identity relationship diagram provides data on the number of jobs, both filled and vacant, including the number of main jobs ${ }^{1}$ and the number of secondary jobs. ${ }^{2}$

\footnotetext{
${ }^{1}$ Labour Account main job is the main activity carried out by an employed person. In the Australian context, this is the job in which most hours are usually worked. An employed person can only have one main job.

${ }^{2}$ Labour Account secondary job is any job held by an employed
} 
In the balanced Labour Account tables, employment estimates from business surveys are reconciled with employment estimates from household surveys to produce a single harmonised Filled Jobs time series. Detailed information on data sources and methods used to compile Jobs data is in the ABS companion publication Australian Labour Account: Concepts, Sources and Methods (cat.no. 6150.0).

\section{Persons}

Explicitly including persons within the sequence of accounts allows not just a more complete understanding of the labour force, it also allows us to bring in the demographic dimension. This provides an opportunity to move beyond an aggregate household view by providing insights into the experience broken down into different demographic groupings such as: gender, age, ethnicity.

The size of the labour force is a measure of the total number of people in Australia who are willing and able to work. It includes everyone who is working or actively looking for work - that is, the number of people employed and unemployed together as one group.

The official measure of the population of Australia is based on the concept of usual residence. This concept refers to all people, regardless of nationality, citizenship or legal status, with some exceptions. By convention, persons are considered to be "usually resident" if they have been or intend to remain in Australia for at least 12 out of 16 consecutive months.

The scope of the population in the Australian Labour Account includes all persons who contribute to Australian economic activity (as defined by the production and territory conventions of the ASNA), irrespective of their residency status.

There is not always a one-to-one relationship between jobs and people, insomuch as a job can be vacant, or one person can have more than one job. Therefore, the number of jobs in an economy will be greater than the number of persons employed.

The Persons quadrant provides statistics on persons employed, persons looking for and available for employment, and persons with potential for further employment. Detailed information on data sources and methods used to compile Persons data is in the ABS companion publication Australian Labour Account: Concepts, Sources and Methods (cat. no. 6150.0).

person, other than their main job. A person can have multiple secondary jobs.

\section{Labour Volume}

The Labour Volume quadrant describes the relationship between the hours of labour that are supplied by individuals and the hours of labour that are used or demanded by enterprises. It quantifies the number of hours worked by persons in all jobs. These data have a direct link to National Accounts and productivity statistics, as they are measures of labour input used in the production of goods and services.

Measuring changes in the level of hours worked for different groups of employed persons is important in order to monitor working and living conditions, as well as analysing economic cycles. Information on hours of work enables various analytical insights such as: classification of employed persons into full-time and part-time status; the identification of underemployed persons; and the creation of aggregate monthly hours worked estimates.

The Labour Force Survey is the primary source for household side hours worked data. Statistics relating to hours paid are based on business survey data, namely the ABS Survey of Employee Earnings and Hours, Australia (cat. no. 6306.0). Detailed information on data sources and methods used to compile Labour Volume data is in the ABS companion publication Australian Labour Account: Concepts, Sources and Methods (cat. no. 6150.0$)$.

\section{Labour Payments}

The Labour Payments quadrant accounts for the costs incurred by enterprises in employing labour and the incomes received by people from their labour provision. It can be described as the cost of labour, and reflects the interactions between jobs, persons and labour volume (hours worked). This is one component of labour already quite well covered by the SNA, and would be expected to be fully consistent with the measures already include within the National Accounts.

The measure of total labour costs is based on the concept of labour as a cost to employers and includes wages and salaries, employers' social contributions (typically superannuation and/or social insurance payments), and all other general employee costs borne by the employer such as training costs, use of recruitment services, payroll tax and so on. Any government subsidies, rebates or allowances for wage and salary payments paid to employers are deducted from employers' labour costs. $\mathrm{S}$ 
Labour Payments data are primarily sourced from underlying data from two ABS National Accounts publications: Australian System of National Accounts (cat. no. 5204.0) and the Australian National Accounts: National Income, Expenditure and Product (cat. no. 5206.0). Detailed information on data sources and methods used to compile Labour Cost data is in the ABS companion publication Australian Labour Account: Concepts, Sources and Methods (cat. no. 6150.0).

\section{Scope adjustments}

Adjustments for scope and conceptual differences between data sources are required in compiling the Australian Labour Account.

Scope adjustments are made in each of the four quadrants in the Australian Labour Account to ensure coherence.

Filled Jobs (business sources) is mainly based on summing estimates from two different business surveys. Data from a third source is added to account for employment in an industry division that was outside the scope of the primary sources. The following scope adjustments are made:

- add the number of persons from known industries excluded from primary business survey sources,

- add the number of persons employed in the permanent defence forces,

- add the number of unpaid contributing family workers,

- add the number of child workers who do not work for an employer as they are excluded from business surveys, and

- subtract the number of persons from specific industry subdivisions duplicated in primary sources to avoid double counting.

Scope adjustments made in one quadrant may be applied to another quadrant, and flow through to a third quadrant, based on the identity relationships.

Filled Jobs (household sources) is based on the number of jobs held by people employed in main jobs and secondary jobs soured from the Labour Force Survey (LFS), which is a household survey. Scope adjustments made to Filled Jobs (household sources) were similar to those made to Filled Jobs (business sources), to align the employed person estimates from the LFS with production boundary and residency concepts present in the business surveys. The following scope adjustments are made to Filled Jobs (household sources) to address LFS scope exclusions:
- add the number of persons employed in the permanent defence forces,

- add the number of child workers,

- add the number of main jobs held by non-resident visitors to Australia, and

- add the number of secondary jobs held by nonresident visitors.

\section{Sources of error}

After adjusting for conceptual and scope differences between data sources, a statistical discrepancy remains between the number of filled jobs as reported by businesses and the number of filled jobs as reported by households.

These discrepancies represent the cumulative impact of data source error, including survey error and modelling error. Survey error includes both sampling error and non-sampling error.

Sampling error is the predictable variability arising from the use of samples, rather than a complete enumeration of the populations of enterprises and households (i.e. a census). It refers to the difference between an estimate for a population based on data from a sample and the 'true' value for that population which would result if a census were taken.

Non-sampling error is caused by factors other than those related to sample selection. Non-sampling error can happen at any stage of a survey and can occur in non-survey data sources. An example of non-sampling error could be missing data or misclassification in government administrative records used directly in the Australian Labour Account. Error could occur in the industry classification of sponsored visa holders, or in the reported number of persons in the permanent defence forces.

Modelling error reflects errors embedded in the modelling assumptions used in the Australian Labour Account, for example in assuming that the proportion of children aged under 15 years who work has remained constant since 2006, or in assuming that quarterly Business Indicators, Australia (cat. no. 5676.0) employment movements accurately reflect quarterly change in the latest available annual data.

\section{Balancing the Australian labour account}

In compiling the Labour Account, residual differences remain between the estimated number of filled 
jobs based on business sources and those derived from household sources. These differences remain after adjusting for known conceptual and scope differences. They represent measurement error in the respective sources, and are reflected in the "statistical discrepancy" series highlighted in the "unbalanced" tables. In the balanced tables, separate business and household estimates have been replaced by a single "filled jobs" estimate. Consequential adjustments are also made to estimates of employed persons, hours worked and hours paid for. The harmonised, or "balanced", filled jobs series are based on a more detailed industry by industry investigation of the underlying sources of measurement error. This process is ongoing, and the balanced tables reflect the current state of this work. Affected series are likely to be subject to further revision.

Two general observations about source data quality are relevant to balancing the estimate of number of filled jobs:

- household side estimates of the number of filled jobs (i.e. LFS data) are considered more reliable at a total economy level, and

- business side data are considered more reliable in estimating the distribution of jobs across industries.

\subsection{Balancing process (Jobs quadrant)}

The following steps were taken to balance estimates of filled jobs in the Australian Labour Account.

Each industry was balanced individually to either the business or household side. This choice was made on the basis of known measurement issues on either side with particular industries, or on the basis that movements on the business or household side were more coherent with other available indicators. Owner Managers of Unincorporated Enterprises (OMUEs) from the Labour Force Survey were also assumed to be misreported and moved to a different industry, if there were no corresponding estimates of Gross Mixed Income on the business side.

The most recent business side annual estimates, for most industries, are based on data which has been extrapolated from an annual benchmarked level from 2016-17. Some minor discretionary adjustments were made to 2017-18 and 2018-19 to bring growth rates in jobs more in line with other indicators, such as Compensation of Employees and Gross Value Added.

Annual Labour Account estimates of filled jobs were then balanced to household sources side at the total economy level.
After balancing the total economy to the household sources side, some industries required further minor discretionary balancing adjustments to bring growth rates in jobs back in line with other available indicators in 2018-19.

There were unusually high or low ratios of hours worked to hours paid for exhibited by some industries. Some hours paid for were adjusted across all industries to rectify this, however total hours paid for at the total economy level was not changed.

\subsection{Adjustments to other quadrants}

Adjustments made to filled jobs through this process have flowed through to two other quadrants in the Australian Labour Account: Persons and Labour Volume.

The number of employed persons was adjusted proportionally with adjustments to filled jobs, after taking account of the level of multiple job holding in the particular industry.

Any adjustments made to filled jobs on the household side had a corresponding adjustment to the number of hours worked. This adjustment was calculated by multiplying the adjustment to filled jobs, by the average hours worked in each industry.

Any adjustments made to filled jobs on the business side had a corresponding adjustment to the number of hours paid for. This adjustment was calculated by multiplying the adjustment to filled jobs, by the average hours paid for in each industry.

\section{Future development}

The Australian Labour Account provides a rich picture of the dynamics of the labour market. For the first time we know how many jobs actually have people in them, and we can estimate people's total hours worked and income across multiple jobs - not just their main job. The Australian Labour Account highlighted that jobs are a characteristic of firms - employment is a characteristic of people.

These insights have already proven extremely valuable to users of economic statistics in Australia, particularly those with an interest in productivity measurement. The ABS intends to continue to build on these labour accounts with a range of potential extensions being considered:

- Regional dimension - moving beyond national level estimates to provide the Labour Account for states and territories. 
- 'Work' Account - expand beyond the SNA production boundary by bringing in estimates of volunteering and unpaid household work to provide a complete articulation of work undertaken.

- Demographic dimension - further utilise the Linked Employee Employer Database to provide a disaggregation describing the experience of different groups of people within the labour market.

\section{Related products and publications}

Detailed information on the Australian Labour Account is available in the ABS publication Australian Labour Account: Concepts, Sources and Methods (cat. no. 6150.0). 